\title{
COX Assembly Mitochondrial Protein 2 Homolog
}

National Cancer Institute

\section{Source}

National Cancer Institute. COX Assembly Mitochondrial Protein 2 Homolog. NCI

Thesaurus. Code C152978.

COX assembly mitochondrial protein 2 homolog (79 aa, $\sim 9 \mathrm{kDa}$ ) is encoded by the human CMC2 gene. This protein may be involved in localization and assembly of complex IV of the mitochondrial electron transport chain. 